\title{
Sinonasal Symptoms and Outcomes in Aircrew
}

\author{
Alzahrani FS, Al-Bar HM*, Algumaan OA, Alqahtani AY and \\ Alzuwayed MA \\ Department of Otolaryngology, Imam Abdulrahman Bin Al Faisal University, Saudi \\ Arabia

\section{Research Article} \\ Volume 3 Issue 2 \\ Received Date: September 06, 2018 \\ Published Date: September 18, 2018 \\ DOI: $10.23880 / 00 A J-16000175$
}

*Corresponding author: Mohammad Al-Bar, Department of Otolaryngology, King Fahad Hospital of the University, Imam Abdulrahman Bin Faisal University (IAU), Alkhobar, Saudi Arabia, Tel: +966 138966666 Ex. 1684; Email: malbar@iau.edu.sa

\section{Abstract}

Background: This study was performed to determine the effect of extended flying time on the Sino-Nasal Outcome Test (SNOT-22) scores of aircrew.

Methodology: A cross-sectional questionnaire was administered to 172 randomly selected aircrew employees (pilots and flight attendants) of Saudi based airlines, collecting demographic data, smoking habit, flying hours, job effects, SNOT22 score, and nasal surgery history. Data were analyzed using SPSS.

Results: When flying time exceeded 12 hours weekly, job performance was affected for $45.4 \%$ of the aircrew. Some $(24.8 \%)$ cancelled their flights because symptoms were intolerable. This was reflected on the SNOT-22 instrument: respondents indicated nasal discharge $(p=0.012)$, ear fullness $(p=0.03)$, or a nasal block $(p=0.004)$.

Conclusion: Flying time of more than 12 hours weekly presents a significant risk for developing many sinonasal symptoms.

Keywords: Chronic rhinosinusitis; Aircrew; Pilot; Flight attendant; Sinonasal outcome test; SNOT-22

Abbreviations: SNOT: Sino-Nasal Outcome Test; IAQ: Indoor Air Quality.

\section{Introduction}

Rhinosinusitis is an important cause of morbidity, anxiety, and lost time from work. Several instruments have been developed to evaluate quality of life for those with rhinosinusitis. The Sino-Nasal Outcome Test (SNOT) score was initially developed as a rhinosinusitis-specific, health-related questionnaire evaluating a combination of symptoms related to the nose and general health. It has been validated as such. Initially, the SNOT score was based on a sixteen-item instrument; it was updated to the SNOT-20, and the most recent version is the SNOT-22 [14].

The SNOT-22 was selected for this study because it is the latest version, including the most recently-added questions related to symptoms of nasal blockage and loss 


\section{Otolaryngology Open Access Journal}

of the sense of smell [3]. Each item is scored on a fivepoint scale where 0 indicates no problems, and 5 indicates maximal problems. This questionnaire is a validated tool used to evaluate how the disease impacts quality of life. It can also be used to study how the amount of flying affects sinonasal symptoms, which can be similar to those of rhinosinusitis. Studies conducted to elucidate the relationship between flying hours and SNOT score cannot yet be found in the literature.

\section{Aim}

To determine if the SNOT-22 score is significantly affected by the amount of time aircrew spend flying.

\section{Methodology}

A cross-sectional questionnaire was administered to 172 aircrew members by convenience sampling pilots and flight attendants of Saudi based airlines starting on 24 May 2016 and ending on 24 August 2016. The questionnaire was used to collect data indicating demographics, smoking habit, flying hours, job effects, SNOT-22 score, and nasal surgery history. Data were analyzed using SPSS. The sample was randomly selected from Saudi based airlines applying a single exclusion criteria known and/or diagnosed rhinosinusitis. Participants with undiagnosed rhinosinusitis might have been included, potentially skewing the results. A statistically validated stratification of the SNOT-22 score is not yet available; therefore, the proposed classification presented by Toma and Hopkins was applied, [4] where a score between (8-20) is considered mild, (21-50) is moderated, and more than 50 is severe. Using SNOT-22 scores, 32 participants were categorized as mild, 42 participants were categorized as moderate and 44 as severe. None of our sample scored more than 100 as demonstrated in Figure 1.

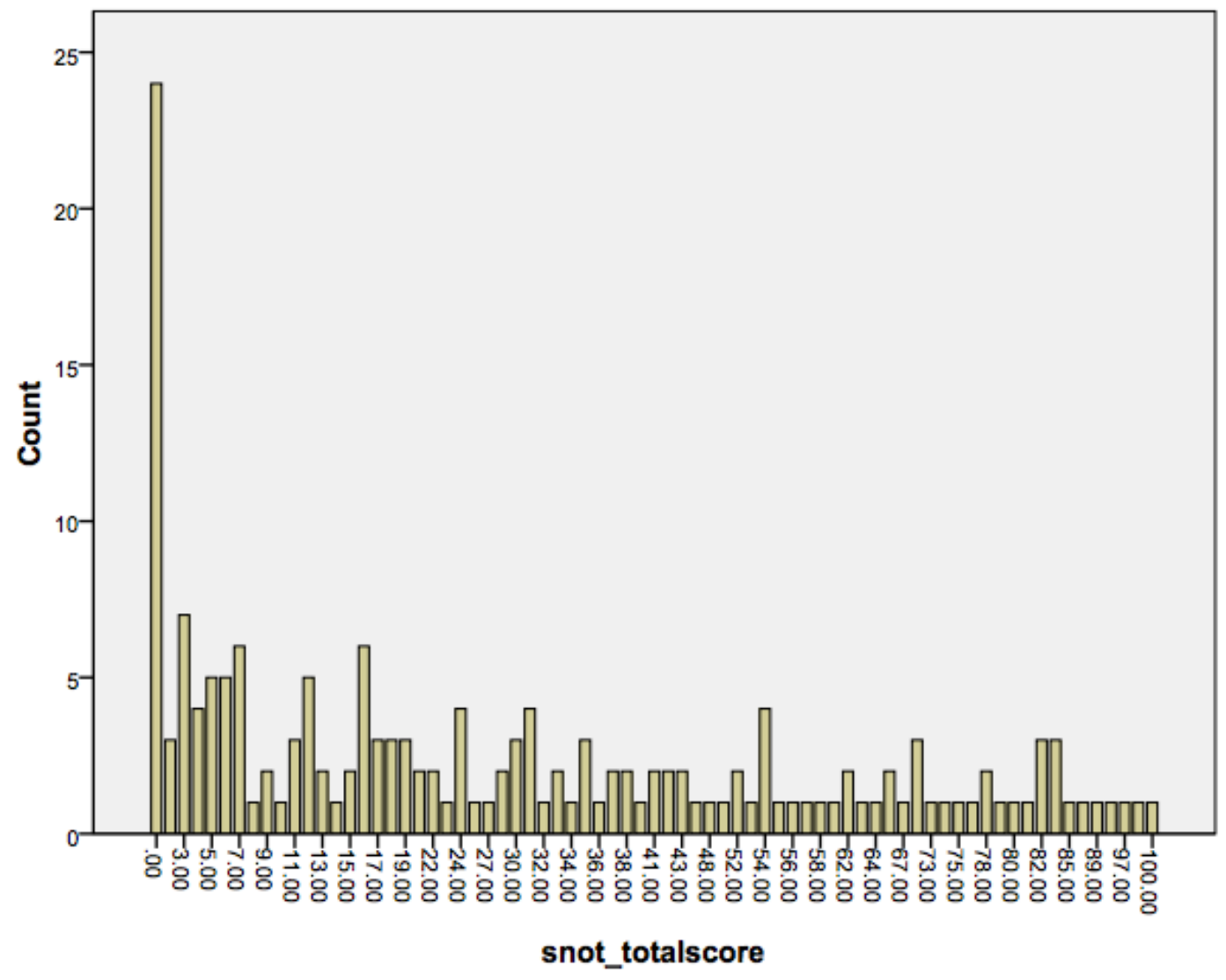

Figure 1: Total SNOT-22 score in the participants. 


\section{Otolaryngology Open Access Journal}

\section{Ethics}

The study protocol was approved by the ethical committee of the center. All participants agreed to take part in the study, and each was allowed to withdraw from the study at any step.

\section{Results}

The SNOT-22 score indicated that quality of life was reduced in both disease specific and general health domains. Nasal discharge was the primary complaint of 94 participants followed by ear fullness (56 participants) and nasal blockage (53 participants). Long flying time (more than 12 hours weekly) was indicated by 56 (34.1\%) participants in our sample. This affected the jobs of $74(45.4 \%)$ participants, and $41(24.8 \%)$ cancelled their flights because the symptoms were intolerable. This was reflected on the SNOT-22 score. The SNOT score changed with statistical significance at 12 hours of weekly flying time for many symptoms: nasal discharge $(\mathrm{p}=$ $0.012)$, ear fullness $(p=0.03)$, nasal block $(p=0.004)$, dizziness $(p=0.025)$, difficulty falling asleep $(p=0.006)$, waking at night $(\mathrm{p}<0.001)$, lack of good night sleep $(\mathrm{p}=$ $0.001)$, waking up tired $(p=0.005)$, fatigue $(p=0.014)$, lack of smell $(p=0.044)$, and thick nasal discharge $(p=$ 0.051).

Several symptoms did not change significantly: nose blowing $(\mathrm{p}=0.444)$, sneezing $(\mathrm{p}=0.187)$, reduced productivity $(\mathrm{p}=0.075)$, reduced concentration $(\mathrm{p}=$ $0.088)$, frustration $(p=0.092)$, cough $(p=0.867)$, postnasal discharge $(p=0.334)$, ear pain $(p=0.127)$, facial pressure pain $(p=0.220)$, sadness $(p=0.213)$, and embarrassment $(p=0.186)$ as shown in Table 1 and Table 2 .

SNOT score changed with statistical significance at 12 hours of weekly flying time for many symptoms as described above. 56 participants (34.1\%) were falling in this category, with male being 53 participants (94\%). 30 participants were smokers (53\%). 10 had previous nasal surgeries (17.8\%), and 4 participants had previous face/nasal trauma $(7.1 \%)$.

\begin{tabular}{|c|c|c|c|c|c|c|}
\hline $\begin{array}{c}\text { Symptom Number of patients } \\
\text { (\% of sample) }\end{array}$ & No problem & Very mild & Mild & Moderate & Severe & As bad as can be \\
\hline Blow nose & $134(77.9)$ & $17(9.9)$ & $8(4.7)$ & $6(3.5)$ & $3(1.7)$ & $4(2.3)$ \\
\hline Block nose & $66(39.5)$ & $22(13.2)$ & $26(15.6)$ & $13(7.8)$ & $28(16.8)$ & $12(7.2)$ \\
\hline Sneeze & $79(47.9)$ & $30(18.2)$ & $28(17.0)$ & $15(9.1)$ & $10(6.1)$ & $3(1.8)$ \\
\hline Nasal discharge & $74(44.0)$ & $27(16.1)$ & $24(14.3)$ & $21(12.5)$ & $17(10.1)$ & $5(3.0)$ \\
\hline Cough & $90(53.6)$ & $21(12.5)$ & $25(14.9)$ & $12(7.1)$ & $12(7.1)$ & $8(4.8)$ \\
\hline Postnasal discharge & $82(48.0)$ & $25(14.6)$ & $20(911.7)$ & $15(8.8)$ & $16(9.4)$ & $13(7.6)$ \\
\hline Thick nasal discharge & $89(51.7)$ & $19(11.0)$ & $25(14.5)$ & $7(4.1)$ & $21(12.2)$ & $11(6.4)$ \\
\hline Ear fullness & $48(28.1)$ & $41(24.0)$ & $26(15.2)$ & $19(11.1)$ & $17(9.9)$ & $20(11.7)$ \\
\hline Dizziness & $92(54.4)$ & $18(10.7)$ & $24(14.2)$ & $11(6.5)$ & $16(9.5)$ & $8(4.7)$ \\
\hline Ear pain & $68(39.5)$ & $29(16.9)$ & $32(18.6)$ & $13(7.6)$ & $16(9.3)$ & $14(8.1)$ \\
\hline Facial pain & $89(52.0)$ & $21(12.3)$ & $25(14.6)$ & $9(5.3)$ & $13(7.6)$ & $14(8.2)$ \\
\hline Sense of taste & $73(43.2)$ & $33(19.5)$ & $26(15.4)$ & $14(8.3)$ & $13(7.7)$ & $10(5.9)$ \\
\hline Difficult fall asleep & $72(42.4)$ & $27(15.9)$ & $26(15.3)$ & $13(7.6)$ & $18(10.6)$ & $14(8.2)$ \\
\hline Wake up night & $75(43.9)$ & $27(15.8)$ & $25(14.6)$ & $17(9.9)$ & $15(8.8)$ & $12(7.0)$ \\
\hline Lack sleep & $69(40.6)$ & $26(15.3)$ & $23(13.5)$ & $22(12.9)$ & $15(8.8)$ & $15(8.8)$ \\
\hline Wake up tired & $63(36.6)$ & $32(18.6)$ & $23(13.4)$ & $15(8.7)$ & $26(15.1)$ & $13(7.6)$ \\
\hline Fatigue day & $59(34.3)$ & $30(17.8)$ & $30(17.8)$ & $13(17.8)$ & $22(13.0)$ & $15(8.9)$ \\
\hline Reduced productivity & $79(46.7)$ & $28(16.6)$ & $22(13.0)$ & $13(7.7)$ & $18(10.7)$ & $9(5.3)$ \\
\hline Reduce concentration & $71(41.3)$ & $33(19.2)$ & $20(11.6)$ & $17(9.9)$ & $20(11.6)$ & $11(6.4)$ \\
\hline Frustrated & $79(45.9)$ & $25(14.5)$ & $22(12.8)$ & $20(11.6)$ & $11(6.4)$ & $15(8.7)$ \\
\hline Sad & $95(55.6)$ & $27(15.8)$ & $12(7.0)$ & $18(10.0)$ & $12(7.0)$ & $7(4.1)$ \\
\hline Embarrassed & $100(60.2)$ & $14(8.4)$ & $19(11.0)$ & $19(11.0)$ & $9(5.4)$ & $5(3.0)$ \\
\hline Ear discharge & $115(67.3)$ & $18(10.5)$ & $15(8.8)$ & $7(4.1)$ & $6(3.5)$ & $10(5.8)$ \\
\hline Hearing prob & $80(47.1)$ & $27(15.9)$ & $25(14.7)$ & $10(5.9)$ & $15(8.8)$ & $13(7.6)$ \\
\hline
\end{tabular}

Table 1: SNOT-22 score in participants. 


\section{Otolaryngology Open Access Journal}

\begin{tabular}{|c|c|c|c|c|}
\hline hours_fly & Less than 4 & 4 to 8 & 8 to 12 & More than 12 \\
\hline Number of patient ( $\%$ of patient) & $53(32.3)$ & $32(19.5)$ & $23(14.0)$ & $56(34.1)$ \\
\hline Age (years) & $20-30$ & $30-40$ & $40-50$ & $50-60$ \\
\hline Number of patient ( $\%$ of patient) & $59(34.5)$ & $52(30.4)$ & $41(24.0)$ & $19(11.1)$ \\
\hline nose_surgery & \multicolumn{2}{|c|}{ Yes } & \multicolumn{2}{|r|}{ No } \\
\hline Number of patient (\% of patient) & \multicolumn{2}{|c|}{$29(17.1)$} & \multicolumn{2}{|c|}{$141(82.9)$} \\
\hline face_accident & \multicolumn{2}{|c|}{ Yes } & \multicolumn{2}{|r|}{ No } \\
\hline Number of patient (\% of patient) & \multicolumn{2}{|c|}{$20(11.9)$} & \multicolumn{2}{|r|}{$141(88.1)$} \\
\hline smoker & \multicolumn{2}{|c|}{ Yes } & \multicolumn{2}{|r|}{ No } \\
\hline Number of patient ( $\%$ of patient) & \multicolumn{2}{|c|}{$66(39.1)$} & \multicolumn{2}{|r|}{$103(60.9)$} \\
\hline cancel_flight & \multicolumn{2}{|c|}{ Yes } & \multicolumn{2}{|r|}{ No } \\
\hline Number of patient (\% of patient) & \multicolumn{2}{|c|}{$41(24.8)$} & \multicolumn{2}{|r|}{$124(75.2)$} \\
\hline Affect job & \multicolumn{2}{|c|}{ Yes } & \multicolumn{2}{|r|}{ No } \\
\hline Number of patient (\% of patient) & \multicolumn{2}{|c|}{$74(45.4)$} & \multicolumn{2}{|r|}{$89(54.6)$} \\
\hline Sex & \multicolumn{2}{|c|}{ Male } & \multicolumn{2}{|r|}{ Female } \\
\hline Number of patient (\% of patient) & \multicolumn{2}{|c|}{$142(84.0)$} & \multicolumn{2}{|r|}{$27(16.0)$} \\
\hline
\end{tabular}

Table 2: Different variables considered in our study as shown.

\section{Discussion}

Paranasal sinuses drain naturally into the nasal cavity through ostia, and these permit mucociliary clearance and ventilation, equilibrating pressure. If obstructed by either inflammation, mucosal thickening, polyps, or anatomical abnormalities, the ostia cannot provide adequate pressure equalization.

People who fly frequently are more likely to be exposed to air pressure changes that can cause the mucosal lining of the sinuses to become edematous, and submucosal bleeding can follow. This can affect the ventilation of the sinuses, particularly if the ostia are involved, resulting in reduced aeration and sinuses filled with fluid or blood [5-7]. This phenomenon is known as sinus barotrauma of aerosinusitis and is aggravated if it is preceded by an upper respiratory tract infection or an allergic episode. Ultimately, facial pain, nasal discharge, and possibly epistaxis can result [8-10]. The pathophysiology of sinus barotrauma is explained by Boyle's Law, which states that the volume of a gas is inversely proportional to the pressure exerted upon it when the temperature is constant $[6,11]$.

During flight, as the plane ascends, air pressure decreases, causing the volume to increase, and the extra volume will escape through the ostia into the nose. As the plane descends, the pressure will increase, condensing the volume and producing a negative pressure. This results in mucosal edema, transudation, and possibly mucosal or submucosal hematoma, which further compromises sinus ventilation and pressure equalization through the sinus ostia. As a result, the sinuses will fill with fluid or blood until the pressure difference is neutralized [6-8,12,13].

A similar chain of events occurs in the middle ear cleft, which naturally drains into the nasopharynx through the Eustachian tube. During rapid decent, negative pressure develops in the middle ear space, and if the tube malfunctions or a nasopharyngeal mass obstructs the tube, the pressure will not equalize. If not resolved, this results in retraction of the tympanic membrane along with transudation, submucosal hematoma, and engorgement of the vessel, ultimately becoming otitis media with effusion [5].

Other factor that might play a role in the sinonasal symptoms is the exposure to the Ozone, which is a wellrecognized respiratory irritant. Commercial airplanes routinely cruise in the upper troposphere or the lower stratosphere, where ozone can reach concentrations of hundreds of parts per billion. Ozone entering the airplane cabin can lead to elevated concentrations (levels exceeding $100 \mathrm{ppb}$, peak levels exceeding $200 \mathrm{ppb}$ ) and increased exposure for passengers and crew. Ozone can be removed from the cabin by catalytic converters. However, many aircraft do not use ozone converters. The converters in use do not always perform well due to surface "poisoning" by various contaminants or imperfect re-furbishing of catalysts during scheduled replacement [13]. 


\section{Otolaryngology Open Access Journal}

Current regulation allows $250 \mathrm{ppb}$ peak ozone concentrations and 100 ppb 3-hour ozone levels in aircraft cabins. These limits exceed the US EPA National Ambient Air Quality Standard (NAAQS) for ground level ozone of $75 \mathrm{ppb}$ over an $8 \mathrm{~h}$ averaging time and the EPA Clean Air Science Advisory Committee recommendation for the NAAQS human-health based standard of between 60 and $70 \mathrm{ppb}$. Effects of ozone and its reaction products on occupants may occur at even lower levels. Ozonerelated symptoms were significantly more frequent on aircraft that flew at high altitudes, presumably due to higher ozone concentrations [13].

There is a long-standing dispute about indoor, and indoor like air humidity and perceived indoor air quality (IAQ) and associated health effects, especially upper airway irritation. Extended exposure to low results in sensory irritation symptoms in eyes and airways, work performance, sleep quality, virus survival, and voice disruption. But the relationship between temperature, humidity, and the virus and aerosol dynamics is complex. Many studies showed both low and high RH, and perhaps even better absolute humidity (water vapor), favors transmission and survival of influenza virus. Research is needed about particle, bacteria and virus dynamics indoors for improvement of quality of life and with more focus on the impact of absolute humidity [14].

These hypotheses might explain our results, which show that aircrew members who fly more than 12 hours weekly of 'flight time', experience worsening nasal discharge, ear fullness, nasal blockage, ear pain, facial pressure pain, and general health issues. European cabin crew association defines 'flight time' as the moments of the duty time when the aircraft first moves under its own power for the purpose of taking-off, until the moment at which it comes to rest after landing.

We hypothesize that by flying less than 12 hours weekly, the body is allowed to recover more efficiently, and statistically different SNOT-22 scores can be prevented. Those who fly more than 12 hours weekly face more stress, and the body sometimes fails to recover from those stresses, resulting in complaints. Although possible confounding factors such as smoking, previous nasal surgery and trauma noted in our sample. Participants with undiagnosed rhinosinusitis also might have been included in our sample, potentially skewing the results.

SNOT score changed with statistical significance at 12 hours of weekly flying time as described above. 56 participants $(34.1 \%)$ were falling in this category, 30 participants were smokers (53\%). 10 had previous nasal surgeries (17.8\%), and 4 participants had previous face/nasal trauma $(7.1 \%)$.

Medical therapy is directed at controlling pain, establishing ventilation, and preventing infection. When medical treatment fails or when recurrent sinus barotrauma occurs because of anatomical abnormalities, surgical intervention should be considered. When underlying mucosal disease (e.g., allergy or polyposis) is comorbid, endoscopic sinus surgery can provide benefits, but ongoing medical therapy might be required for maximal results.

\section{Conclusion}

Flying time for at least 12 hours weekly presents a significant risk for developing many sinonasal symptoms. A more extensive study must be performed to validate these results. Additionally, objective measures that can be used to diagnose rhinosinusitis or nasal polyposis by nasal endoscopy or CT evaluation would be useful so that symptomatic patients can be selectively excluded.

\section{References}

1. Piccirillo JF, Merritt Jr MG, Richards ML (2002) Psychometric and clinimetric validity of the 20- item Sino-Nasal Outcome Test (SNOT-20). Otolaryngol Neck Surg 126(1): 41-47.

2. Piccirillo JF, Edwards D, Haiduk A, Yonan C, Thawley SE (1995) Psychometric and clinimetric validity of the 31-item rhinosinusitis outcome measure (RSOM31). Am J Rhinol 9(6): 297-306.

3. Hopkins C, Gillett S, Slack R, Lund VJ, Browne JP (2009) Psychometric validity of the 22-item Sinonasal Outcome Test. Clin Otolaryngol 34(5): 447-454.

4. Toma S, Hopkins C (2016) Stratification of SNOT-22 scores into mild, moderate or severe and relationship with other subjective instruments. Rhinology 54(2): 129-133.

5. Zadik Y (2009) Aviation dentistry: current concepts and practice. Br Dent J 206(1): 11-16.

6. Weitzel EK, McMains KC, Rajapaksa S, Wormald PJ (2008) Aerosinusitis: pathophysiology, prophylaxis, and management in passengers and aircrew. Aviat Space Environ Med 79(1): 50-53. 


\section{Otolaryngology Open Access Journal}

7. Weitzel MEK, McMains KC, Wormald PJ (2009) Comprehensive surgical management of the aerosinusitis patient. Curr Opin Otolaryngol Head Neck Surg 17(1): 11-17.

8. O'reilly BJ, Lupa H, Mcrae A (1996) The application of endoscopic sinus surgery to the treatment of recurrent sinus barotrauma. Clin Otolaryngol 21(6): 528-532.

9. Vaezeafshar R, Psaltis AJ, Rao VK, Zarabanda D, Patel ZM, et al. (2017) Barosinusitis: Comprehensive review and proposed new classification system. Allergy Rhinol 8(3): 109-117.

10. Stewart JTW (1979) Common otolaryngologic problems of flying. Am Fam Physician 19(2): 113-119.
11. McGibbon JEG (1944) Nasal Sinus Pain Caused by Flying (The Syndrome of Sinus Barotrauma): An Analysis of 145 Cases. J Laryngol Otol 59(11): 405427.

12. Uzun C (2009) Paranasal sinus barotrauma in sports self-contained underwater breathing apparatus divers. J Laryngol Otol 123(1): 80-84.

13. Bekö G, Allen JG, Weschler CJ, Vallarino J, Spengler JD (2015) Impact of cabin ozone concentrations on passenger reported symptoms in commercial aircraft. PLoS One 10(5): e0128454.

14. Wolkoff $P$ (2018) Indoor air humidity, air quality, and health--An overview. Int J Hyg Environ Health 221(3): 376-390.

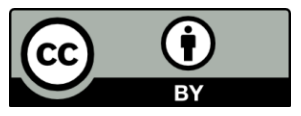

Mohammad Al-Bar, et al. Sinonasal Symptoms and Outcomes in Aircrew. Otolaryngol 